\title{
Advances in life cycle analysis, econometrics, optimization, R\&D policy, and health decision making
}

\author{
Zachary A. Collier $^{1} \cdot$ James H. Lambert $^{1} \cdot$ Igor Linkov $^{2}$
}

Published online: 7 August 2017

(C) Springer Science+Business Media, LLC 2017

The September issue of Environment Systems and Decisions contains articles that cover an interdisciplinary spectrum of topics (e.g., climate change, human health, research policy) and methodological innovations (e.g., life cycle assessment, econometrics, optimization).

The issue opens with a review article exploring governance implications for environmental and occupational health associated with pesticide use (Shammi et al. 2017). Next, Abrahams et al. (2017) use cost and life cycle greenhouse gas emissions data to optimize the global trade network for crude oil. Fatorić et al. (2017) document stakeholder perceptions related to effects of climate change risk on employment and migration. Next, a mixed integer programming model is presented for the optimization of multiple economic, social, and environmental objectives in municipal solid waste site selection ( $\mathrm{Yu}$ and Solvang 2017). Macnee and Tokai (2017) describe a method for calculating health impacts including cardiovascular disease and disaster-related injuries attributed to climate change. The energy efficiency and cost-effectiveness of photovoltaics is assessed when considering the tilt angles of the panels as well as synergies with other roofing types (Statler et al. 2017). With a multi-criteria decision model, Loc et al. (2017) evaluate the benefits of various urban flood control alternatives. Islam et al. (2017) document the prevalence of arsenic in the food chain and assess the health risks from

Igor Linkov

Igor.Linkov@usace.army.mil

Zachary A. Collier

zac4nf@virginia.edu

University of Virginia, Charlottesville, VA, USA

2 US Army Engineer Research and Development Center, Concord, MA, USA ingestion of various foods. Econometric methods are employed by Magazzino (2017) to investigate the relationship between economic growth of nations, their energy consumption, and greenhouse emissions. Finally, Keisler et al. (2017) develop and demonstrate a decision model that can be used to allocate research funding to scientists.

For the Springer journal Environment Systems and Decisions, the recent release of Google Scholar's (https:// scholar.google.com/) metrics indicate positive trends. The h5-index for Environment Systems and Decisions rose to 16 (from 14 the previous year), and the h5-median is 24 . Additionally, of all journals with the word "Decision" in the title, Environment Systems and Decisions is ranked 16th. This shows an upward trajectory in the impact of the research and case studies that have been published in the journal in the recent four years.

Upcoming issues of interest in Environment Systems and Decisions include (1) Brunswik's theory of probabilistic functionalism, (2) food security, (3) resilience in sociotechnical systems, and (4) emerging technologies.

Finally, in coordination with the Society for Risk Analysis (http://www.sra.org/), in particular the SRA Decision Analysis and Risk Specialty Group (DARSG), the ESD Editorial Board is pleased to announce the annual ESD Best Paper Award for innovative advancement in the theory and practice of decision analysis, systems engineering, and related topics. The DARSG has nominated three abstracts from the upcoming SRA annual meeting, which are invited to submit full-length manuscripts to Environment Systems and Decisions. Manuscripts will be evaluated by the President of the DARSG and the Editorial Board to select the Best Paper(s). The winner(s) of the Best-Paper Award will share \$500. Each accepted paper will be eligible for expedited online and print publication in an upcoming issue. 


\section{References}

Abrahams LS, Samaras C, Griffin WM, Matthews HS (2017) Effect of crude oil carbon accounting decisions on meeting global climate budgets. Environ Syst Decis. doi:10.1007/s10669-0179638-5

Fatorić S, Morén-Alegret R, Niven RJ, Tan G (2017) Living with climate change risks: stakeholders' employment and coastal relocation in mediterranean climate regions of Australia and Spain. Environ Syst Decis. doi:10.1007/s10669-017-9629-6

Islam MS, Ahmed MK, Habibullah-Al-Mamun M, Eaton DW (2017) Arsenic in the food chain and assessment of population health risks in Bangladesh. Environ Syst Decis. doi:10.1007/s10669017-9635-8

Keisler JM, Foran CM, Kukjla MM, Linkov I (2017) Undue concentration of research and education: multi-criteria decision approach to assess jurisdiction eligibility for NSF funding. Environ Syst Decis. doi:10.1007/s10669-017-9650-9

Loc HH, Duyen PM, Ballatore TJ, Lan NHM, Gupta AD (2017) Applicability of sustainable urban drainage systems: an evaluation by multi-criteria analysis. Environ Syst Decis. doi:10.1007/ s10669-017-9639-4
Macnee RGD, Tokai A (2017) The development of a method to determine the burden of climate change on different health outcomes at a local scale: a case study in Osaka Prefecture, Japan. Environ Syst Decis. doi:10.1007/s10669-017-9636-7

Magazzino C (2017) The relationship among economic growth, $\mathrm{CO}_{2}$ emissions, and energy use in the APEC countries: a panel VAR approach. Environ Syst Decis. doi:10.1007/s10669-017-9626-9

Shammi M, Hasan N, Rahman MM, Begum K, Sikder MT, Bhuiyan MH, Uddin MK (2017) Sustainable pesticide governance in Bangladesh: socio-economic and legal status interlinking environment, occupational health and food safety. Environ Syst Decis. doi:10.1007/s10669-017-9628-7

Statler NE, Adams AM, Eckmann TC (2017) Optimizing angles of rooftop photovoltaics, ratios of solar to vegetated roof systems, and economic benefits, in Portland, Oregon, USA. Environ Syst Decis. doi:10.1007/s10669-017-9640-y

Yu H, Solvang WD (2017) A multi-objective location-allocation optimization for sustainable management of municipal solid waste. Environ Syst Decis. doi:10.1007/s10669-017-9632-y 